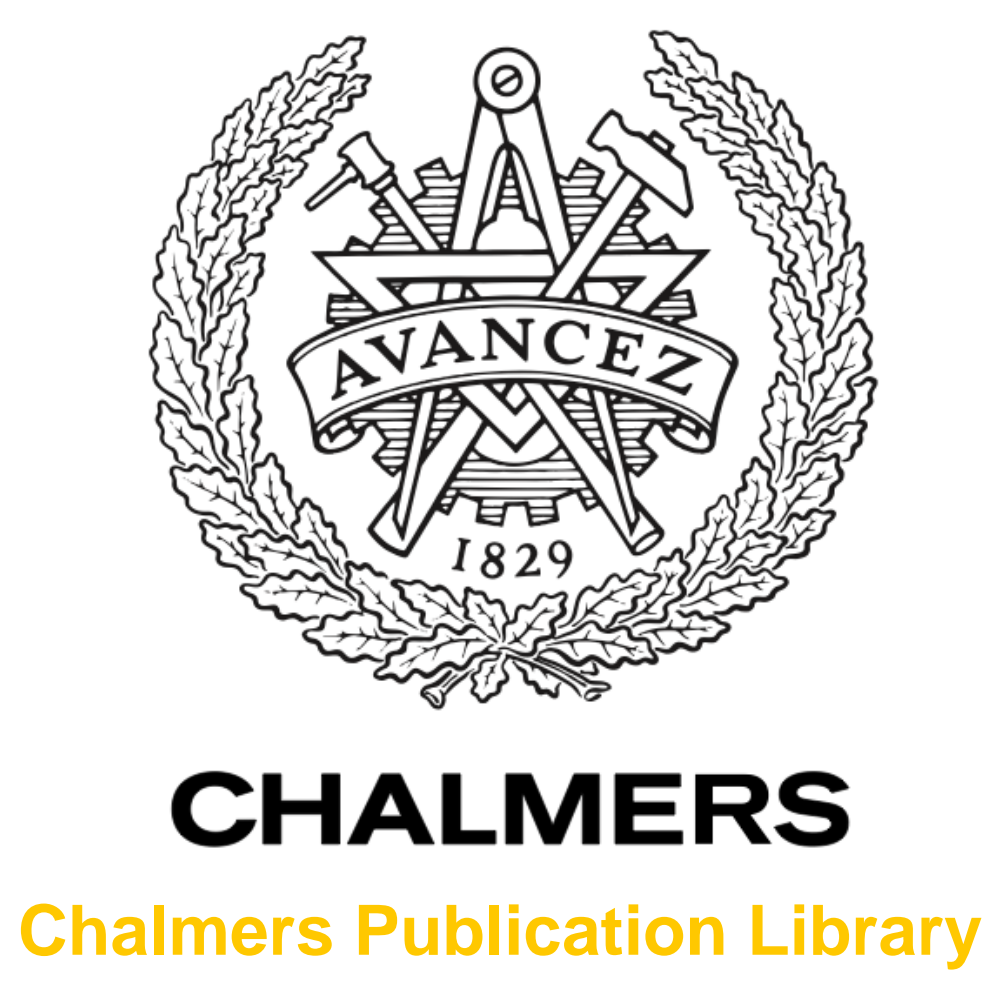

Enhanced strut-and-tie model for reinforced concrete pile caps

This document has been downloaded from Chalmers Publication Library (CPL). It is the author's version of a work that was accepted for publication in:

International Association for Bridge and Structural Engineering, 39th IABSE Symposium Engineering the Future, September 21-23, 2017, Vancouver, Canada

Citation for the published paper:

Mathern, A. ; Chantelot, G. ; Svahn, P. et al. (2017) "Enhanced strut-and-tie model for reinforced concrete pile caps". International Association for Bridge and Structural

Engineering, 39th IABSE Symposium - Engineering the Future, September 21-23, 2017,

Vancouver, Canada pp. 607-614.

Downloaded from: http://publications.lib.chalmers.se/publication/252933

Notice: Changes introduced as a result of publishing processes such as copy-editing and formatting may not be reflected in this document. For a definitive version of this work, please refer to the published source. Please note that access to the published version might require a subscription. 


\title{
Enhanced strut-and-tie model for reinforced concrete pile caps
}

\author{
Alexandre Mathern \\ NCC Sverige AB / Chalmers University of Technology, Gothenburg, Sweden
}

\section{Gautier Chantelot}

GAMACO Ingénieurs-Conseils S.A., Liège, Belgium

\section{Per-Ola Svahn, Per Kettil}

Skanska Sverige $A B$, Gothenburg, Sweden

\section{Rasmus Rempling, Björn Engström}

Chalmers University of Technology, Gothenburg, Sweden

Contact: alexandre.mathern@chalmers.se

\begin{abstract}
Strut-and-tie models provide a simple and rational way to design discontinuity regions in reinforced concrete structures. However, when it comes to three-dimensional concrete elements such as pile caps, enhancements are needed to ensure a reliable and not overly conservative design. This paper presents an enhanced strut-and-tie model adapted to the analysis and design of reinforced concrete pile caps. The model is based on consistent geometries of three-dimensional nodal zones and struts and integrates a strength criterion for confined bottle-shaped struts. An iterative process is used in order to optimize the position of the members by refining the dimensions of the nodal zones. The model is validated by experimental results from tests on fourpile caps reported in the literature, showing effective predictions of their ultimate capacities. This enhanced strut-and-tie model can lead to safe and less conservative design of pile caps.
\end{abstract}

Keywords: strut-and-tie model, pile caps, reinforced concrete, three-dimensional.

\section{Introduction}

Pile caps are common structural elements for piled foundations of bridges or buildings located in areas where the superficial layers of the soil cannot provide sufficient bearing capacity. The function of pile caps is to transfer the loads from columns or walls of the superstructure, in a safe manner, to a group of piles into the ground.
A specificity of pile caps, compared to most of the other types of structural elements (e.g. beams, slabs, walls, etc.), is that they typically have large dimensions in all three directions and a pronounced three-dimensional stress field.

Because of this geometrical feature, pile caps are often in a range of dimensions where the whole pile cap constitutes a discontinuity region and assumption of plane sections is not valid. 
Therefore common design procedures based on sectional approaches are questionable for pile caps.

A suitable alternative is to base the design on a three-dimensional strut-and-tie model and to consider all load effects simultaneously, by using a hypothetical equivalent truss to represent the complete transfer of forces in the structure. The truss consists of struts (concrete) and ties (reinforcing steel), which carry respectively compressive and tensile stresses and are connected at the nodes.

The strut-and-tie method is based on the lower bound theorem of the theory of plasticity [1]. It consists in assuming a stress field, which is in equilibrium with the external loads and respects the design criteria at any point of the structure. Then, assuming that the structure has enough ductility to satisfy any needed redistribution of forces, the failure load obtained by this method underestimates the theoretical failure load of the structure. In other words: "the structure will always find, if not the same, a more efficient way to carry the load".

Nowadays, most of the major codes of practice allow the use of strut-and-tie models. The Canadian Concrete Code was one of the first standards to include it, in 1984, as an alternative for shear design in regions including static or geometrical discontinuities. The design according to stress fields using the strut-and-tie method became an alternative for the structural analysis of discontinuity regions in the CEB FIP Model Code 1990. Strut-and-tie models were then introduced into the $\mathrm{ACl}$ Building Code in 2002. The Appendix A "Strut-and-tie models" was created and different parts of the codes were modified to allow the design with strut-and-tie models. In 2004, the strut-and-tie method was introduced into Eurocode 2, in Section 5.6.4 "Analysis with strut-and-tie models" and Section 6.5 "Design with strut-and-tie models".

Several studies have been conducted on the design of pile caps by strut-and-tie models, in particular by Adebar and Zhou [2] and Souza et al. [3]. The results of these studies and the conclusions drawn by the authors, highlight the potential of using strut and-tie models for the design of pile caps.

However, most of the time, authors do not expand on detailing for three-dimensional strutand-tie models, for instance concerning verification of nodes.

Even if some books and articles mention the case of three-dimensional strut-and-tie models, most of the potentially three-dimensional problems found in the literature are solved by a combination of two-dimensional models following each plane of the structural element. Furthermore, most of the articles about threedimensional strut-and-tie models do not specify how to consider the intersection between struts and ties and how to define the geometry and check the nodal zones. It is often likely that the authors use 2-D analogy in their models.

The aim of this study is to develop an enhanced and generic three-dimensional strut-and-tie model adapted to the design and analysis of pile caps.

Innovative characteristics of the strut-and-tie model developed are: (1) that it is based on consistent geometries of three-dimensional nodal zones; (2) that the sizes of nodal zones are refined according to the state of stress in the nodal zones; and (3) that the geometry of the strut-and-tie model is improved by an automated iterative process to decrease internal forces and better utilize the strength of the nodal zones. Furthermore, the model integrates a strength criterion to check bottle-shaped compressive struts confined by plain concrete.

\section{Enhanced strut-and tie model for four-pile caps}

A strut-and-tie model is developed in this work, to analyse and design reinforced concrete pile caps without shear reinforcement loaded by vertical forces from a column. The model, which includes all the characteristics described in this Section, is hereinafter referred to as Enhanced Model.

\subsection{Geometry of the strut-and-tie model}

The general geometry of the strut-and-tie model used to analyse four-pile caps in this study is 
illustrated in Figure 1, where struts are indicated by dashed lines and ties by continuous lines.

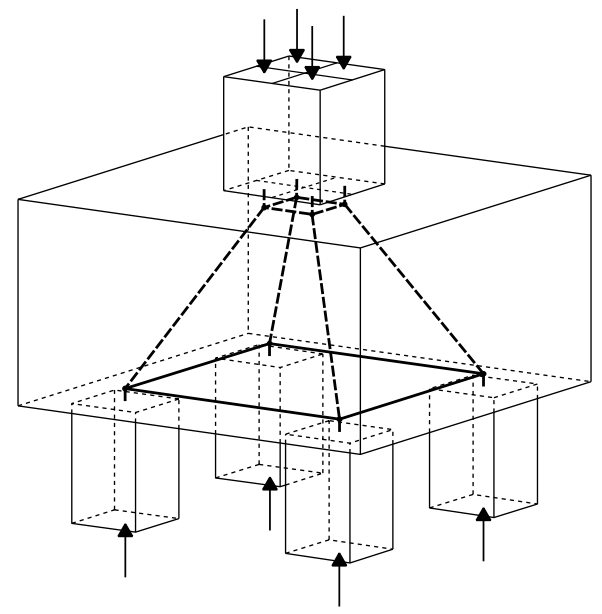

Figure 1. Strut-and-tie model for four-pile caps

\subsection{Three-dimensional nodal zones}

In this paper, a solution is proposed, to ensure a consistent geometry for the verification of the three-dimensional nodal zones where struts and ties, which are not in the same plane, converge. This solution is based on nodal zones with parallelepiped shapes and inclined struts with hexagonal cross-sections, as illustrated in Figure 2.

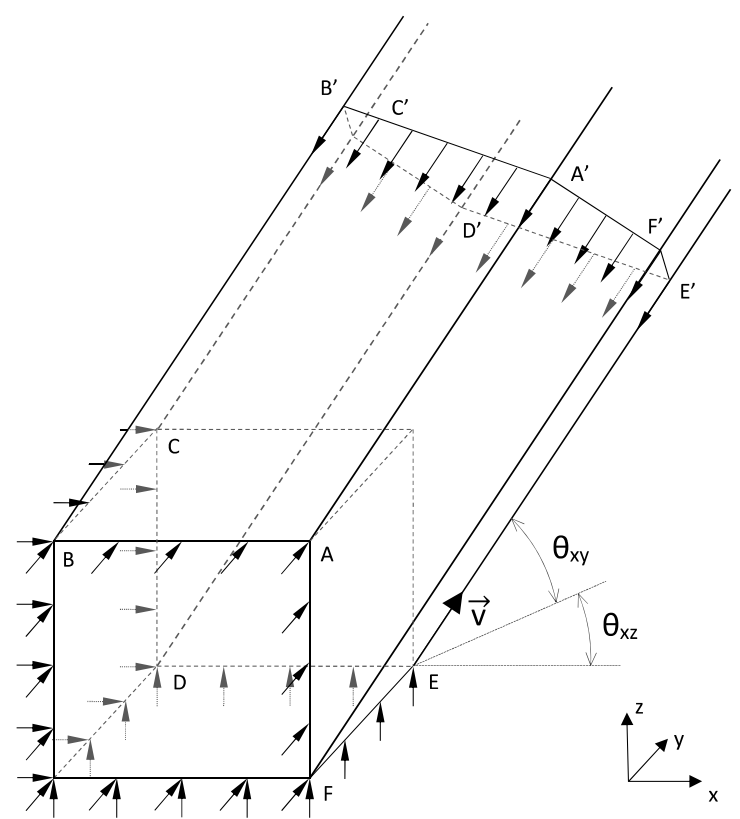

Figure 2. Nodal zone geometry of a node with an incoming inclined strut with hexagonal cross section.

In the Enhanced Model, the hexagonal crosssectional area of the inclined struts is computed both at the nodal zones under the column and at the ones above the piles in order to check the stresses at the nodes. Knowing the coordinates of the border points of each nodal zone (i.e. the corners of the parallelepiped), it is possible to calculate the distance between their projections in a plane orthogonal to the vector $\vec{v}$, defining the axis of the strut.

$$
\vec{v}=\left(\cos \theta_{x y} \cos \theta_{x z}, \cos \theta_{x y} \sin \theta_{x z}, \sin \theta_{x y}\right)
$$

For instance, if $A$ and $B$ are two points at corners of the nodal zone situated on adjacent edges of the hexagonal strut (Figure 2), the distance between their respective projections $A^{\prime}$ and $B^{\prime}$ in a plane orthogonal to the axis of the strut is:

$$
A^{\prime} B^{\prime}=\left\|\overrightarrow{A B}-\left(\overrightarrow{A B} \cdot \vec{v}^{T}\right) \cdot \vec{v}\right\|
$$

The cross-sectional area of the strut $A_{\text {strut }}$ can then be easily obtained by dividing the hexagon into four triangles. Heron's formula can be used to calculate the area $A_{t r i}$ of each of these triangles, knowing the length $l_{i}$, of its sides:

$$
A_{t r i}=\frac{1}{4} \sqrt{\left(\sum_{i=1}^{3} l_{i}^{2}\right)^{2}-2 \sum_{i=1}^{3} l_{i}^{4}}
$$

The solution proposed ensures that static equilibrium is fulfilled at the nodes and that the faces of the nodal zones are compatible with the cross-sectional areas of the struts and ties meeting at the node.

This nodal zone geometry is suitable for both the nodes at the column and the piles in the strutand-tie model considered for four-pile caps. It can also be extended to other types of threedimensional nodes for more complex strut-and-tie models.

The improvements proposed are justified by the importance of checking the strength of nodal zones in the design by strut-and-tie models.

\subsection{Refinement of nodal zones}

The exact position of the nodes needs to be assigned in order to define the geometry of the model, calculate the forces in the members and 
design or check the capacity of the struts, the ties and the nodes.

The vertical position of the nodes depends on the level of horizontal struts and ties, i.e. on $a_{s}$ the level of the flexural reinforcement axis for the bottom nodes and on $a_{c}$ the level of the horizontal concrete struts under the columns for the top nodes (as shown in Figure 4).

It is convenient to choose the same height for the axis of flexural reinforcement in the two directions for the whole pile cap in order to simplify the design of the strut-and-tie model and the detailing of the nodal zones.

In strut-and-tie modeling, nodes that are directly subjected to external loads are commonly positioned on the axis of the torque-free resultant of the forces at a certain loaded area. Therefore, in the model considered, the horizontal position of the nodes would usually correspond to the centroid of the cross section of the piles or the centroid of the quadrants of the column's area.

However, in this work, a further improvement of the model is proposed by refining the nodal zones under the column, according to the theory of plasticity.

The improvement consists in reducing the horizontal area of the four nodal zones under the column in order to space them out at the corners of the column's area, as illustrated in Figure 3. In this way, the nodes at the middle of these nodal zones become closer to the bottom nodes above the piles, thereby reducing the forces in the inclined struts and the bottom ties.

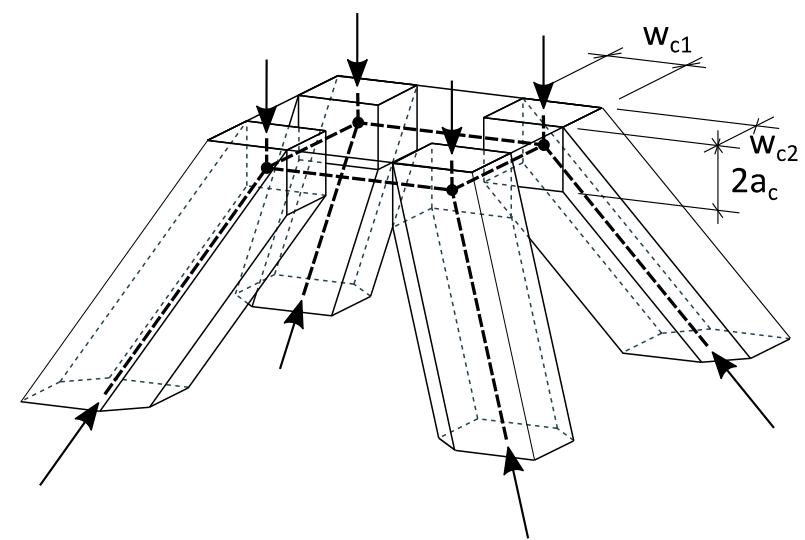

Figure 3. Refinement of nodal areas used in the strut-and-tie model under the column
The choice of the horizontal and vertical dimensions for the parallelepiped nodal zones under the column is done iteratively in order to minimize the forces in the members while ensuring acceptable stress levels on the faces of the nodal zones and in the incoming struts (see Section 2.5).

The stresses on the bearing area under the column and the stresses on the other faces of these nodal zones are checked by taking advantage of the favourable triaxial compression state of stress in the nodal zones. The maximum allowable stresses are calculated according to provisions from Eurocode 2 [4] for triaxially compressed nodes:

$$
\sigma_{R, \max }=k_{4}\left(1-\frac{f_{c k}}{250}\right) f_{c}
$$

With:

$$
k_{4}=3.0
$$

Where $f_{c k}$ is the characteristic compressive cylinder strength of concrete at 28 days.

The concrete compressive cylinder strength $f_{c}$, used in this paper, refers either to the design value $f_{c d}$ according to Eurocode 2 [4], or to the mean value $f_{c m}$ when the model is used to predict the ultimate capacity of pile caps.

This refinement of nodal zones can be particularly favourable in the design of pile caps due to the usually large loading area at the column and the influence of the strut inclinations on the forces in the members.

It should be noted that this method assumes that some transverse tensile capacity is provided in the discontinuity region of the column above the pile cap.

\subsection{Strength criterion for confined bottle- shaped struts}

It is of particular importance, when designing with strut-and-tie models, to check the state of stress in critical concentrated regions. However, in some cases the failure may be dependent on what happens away from these nodal zones. It is the case for instance when there is space for 
compressive stresses to spread laterally around the struts, which gives rise to perpendicular tensile stresses. These so-called bottle-shaped struts are therefore prone to failure by combined splitting and crushing of the concrete.

However, previous studies have shown that the splitting strength of struts surrounded by large volumes of inactive concrete was enhanced by confinement effects [5].

Adebar and Zhou [5] concluded, from analytical and experimental studies of double-punch tests, that the maximum bearing stress is dependent on the ratio of the cylinder height to the bearing diameter $H / d$ and on the ratio of the cylinder diameter to the bearing diameter $D / d$.

A strength criterion is used, in the Enhanced Model, for the strength of the inclined struts, which represent the bottle-shaped stress fields. This criterion is based on the formulation of Adebar and Zhou [5] for the maximum bearing stress for unreinforced compressive struts confined by plain concrete and subjected to a perpendicular tension field.

The inclined struts in the Enhanced Model are idealised as concrete cylinders with dimensions dependent on the geometries of the pile caps and the nodal zones, as shown in Figure 4.

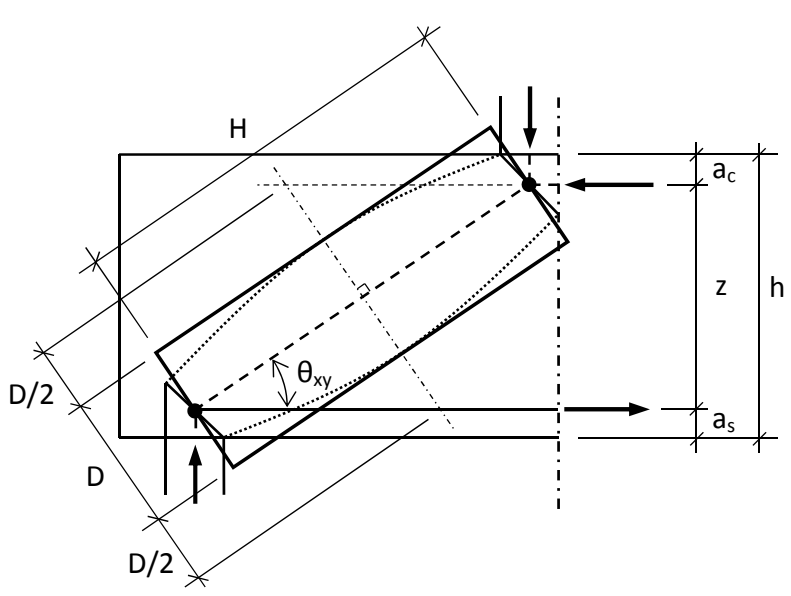

Figure 4. Transfer of forces in a confined bottleshaped strut and equivalent cylinder used for strength criterion.

The cylinder length, $H$, is considered to be equal to the distance between the nodes at the column and at the pile, i.e. the length of the inclined strut. The cylinder diameter, $D$, is defined as half the length of a segment perpendicular to the axis of the inclined strut and fitting between the resultants of the horizontal forces in the concrete (top) and the steel (bottom), i.e.:

$$
D=\frac{z}{2 \cos \theta}=\frac{h-a_{c}-a_{s}}{2 \cos \theta}
$$

The bearing diameter is defined as the equivalent average diameter of the supports, $d_{\text {mean }}$, considering the hexagonal area of the inclined strut at the nodal zones of the column $A_{c o l}$ and the piles $A_{\text {pile: }}$ :

$$
d_{\text {mean }}=\sqrt{\frac{2\left(A_{\text {col }}+A_{\text {pile }}\right)}{\pi}}
$$

According to the formulation of Adebar and Zhou [5], the strength criterion for the cracked inclined struts, which is used in the Enhanced Model, is expressed as the maximum allowable bearing stress, $\sigma_{R, \max }$ :

$$
\begin{gathered}
\sigma_{R, \max }=0.6 f_{c}(1+2 \alpha \beta) \\
\text { for } f_{c} \leq 34.5 \mathrm{MPa} \\
\sigma_{R, \max }=0.6 f_{c}\left(1+\alpha \beta \frac{10}{\sqrt{f_{c}}}\right) \\
\text { for } f_{c}>34.5 \mathrm{MPa}
\end{gathered}
$$

With:

$$
\begin{aligned}
& \alpha=\frac{1}{3}\left(\frac{D}{d_{\text {mean }}}-1\right) \leq 1 \\
& \beta=\frac{1}{3}\left(\frac{H}{d_{\text {mean }}}-1\right) \leq 1
\end{aligned}
$$

\subsection{Iterative design procedure}

The maximum capacity for a specific pile cap is determined by an iterative procedure. In this process, the height $\left(2 \cdot a_{c}\right)$ and the horizontal dimensions $\left(w_{c 1}\right.$ and $\left.w_{c 2}\right)$ of the parallelepiped nodal zones under the column (Figure 3 ) are varied within predefined intervals of geometrically acceptable values in order to find the geometry of the strut-and-tie model resulting in the maximum capacity. 
For each geometry of the model, the computed forces in the members are checked with regard to their respective capacity:

- Tensile stresses in the reinforcing steel with regard to its yield strength

- Compressive stresses on the faces of the concentrated nodes under the column and over the piles (bearing stresses, stresses from the inclined struts and horizontal stresses under the column) with regard to the maximum admissible stresses at nodal zones

- Compressive stresses in the inclined struts with regard to the strength of bottleshaped struts confined with concrete

The maximum capacity is found by increasing incrementally the column load until no models fulfill all the aforementioned design criteria, after considering all possible combinations of the parameters $w_{c 1}, w_{c 2}$ (which are equal in the case of a square pile cap with a square column) and $a_{c}$. In order to save computational time in previous iterations, the load can be incremented as soon as one satisfactory geometry is found.

\section{Comparison with experimental results}

Experimental results from studies on four-pile caps without shear reinforcement, reported in the literature, are used in order to validate the strutand-tie model described in this paper.

The comparison is based on failure loads obtained experimentally for 24 pile caps, tested by Blévot and Frémy [6], Clarke [7], Sabnis and Gogate [8] and Suzuki et al. [9], [10]. Pile caps with different reinforcement layouts are considered; 13 pile caps had grid reinforcement, 7 had bunched reinforcement placed in square over the piles and 4 had a combination of bunched square and grid reinforcement.

All the pile caps considered had a square base and a constant height, except the ones tested by Blévot and Frémy [6], which had a conical shape. Hence, the variable height of the latter is taken into account in the predictions through a reduction of the confinement provided to the inclined struts, which is achieved by decreasing the diameter of the equivalent cylinder considered in the calculation of the strength criterion.

As circular piles or columns were used in few of the tests, these are transformed to equivalent squares in the analyses with strut-and-tie models assuming the same cross sectional area and an orientation determined by the one of the bending reinforcement.

The pile caps are analysed with the Enhanced Model, including all the characteristics described in Section 2, in order to predict their maximum capacity. They are also analysed with three alternative models (Alternative 1-3), each of them omitting one of the characteristics, in order to study the influence of these characteristics. Alternative 1 , disregards the horizontal refinement of the nodal zones under the column and the triaxial strength criterion, Alternative 2 omits the effects of confinement for the strength of inclined struts and Alternative 3 uses twodimensional analogy for the geometry of the nodal zones.

Except for the strength criterion for inclined struts described in Section 2.4, verifications are based on provisions for design with strut-and-tie models presented in Eurocode 2 [4].

Mean values of the cylinder compressive strength of concrete are used to predict the failure loads of the pile caps.

The maximum capacity of each pile cap is determined by the iterative procedure previously described, using an automated program based on Matlab. The predicted failure load, which is considered in the comparison with experimental results, corresponds to the maximum column load for which all the design criteria are fulfilled. 


\section{Results}

Ratios obtained between the experimental failure load and the one predicted with the Enhanced Model are represented in Figure 5.

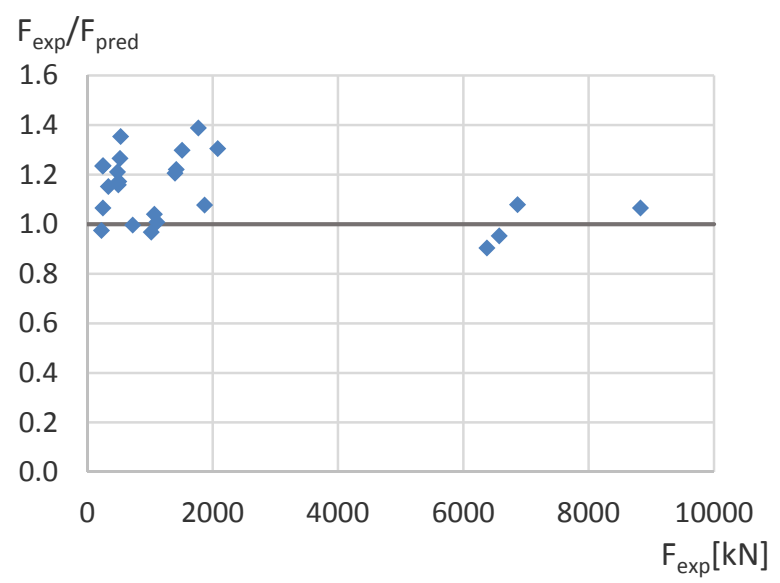

Figure 5. Ratio of measured-to-predicted failure loads for the Enhanced Model.

Ratios of experimental-to-predicted failure loads obtained with the Enhanced Model and the three alternative models and their standard deviations are presented in Table 1.

Table 1. Comparison of failure loads obtained experimentally and predicted with the strut-andtie models.

\begin{tabular}{|c|c|c|c|c|}
\hline & 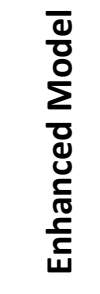 & 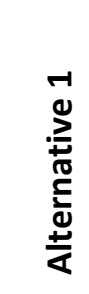 & 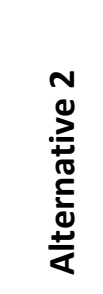 & 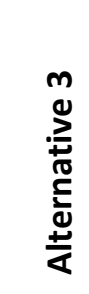 \\
\hline 3-D nodal zones & $\checkmark$ & $(\checkmark)$ & $\checkmark$ & \\
\hline Refinement nodes & $\checkmark$ & & $\checkmark$ & $\checkmark$ \\
\hline Confinement strut & $\checkmark$ & $(\sqrt{ })$ & & $\checkmark$ \\
\hline $\begin{array}{l}\text { Iterative } \\
\text { improvement }\end{array}$ & $\checkmark$ & $\checkmark$ & $\checkmark$ & $\checkmark$ \\
\hline Average $F_{\text {exp }} / F_{\text {pred }}$ & 1.14 & 1.53 & 1.25 & 1.08 \\
\hline $\begin{array}{l}\text { Standard } \\
\text { deviation }\end{array}$ & 0.12 & 0.35 & 0.15 & 0.17 \\
\hline
\end{tabular}

\section{Discussion}

The strut-and-tie model developed in this work includes several innovative characteristics that are specially adapted to the design of pile caps.

Predictions of the failure loads of the 24 pile caps considered using the Enhanced Model including all these characteristics are in good agreement with the failure loads experimentally obtained, with a low standard deviation of the ratios of measuredto-predicted failure loads.

In the predictions of the failure loads, not including the refinement of the nodal zones and higher strength limits for triaxially compressed nodes, leads to the most conservative predictions with a large spread. Hence in Alternative 1, considering or not three-dimensional nodal zones and the strength criteria for bottle-shaped struts has almost no influence for most of the pile caps considered.

The refinement of the nodal zones appears to be essential in order to avoid a too conservative design for pile caps with strut-and-tie models. Through plastic redistribution a reduction of the forces in the members is achieved, as well as an improved triaxial state of stress at the nodal zone under the column, which allows to use a higher stress limit according to Eurocode 2 [4].

When considering refinement of nodal zones and triaxial compression, results obtained with Alternative 2 highlight that the use of the strength criteria for confinement and three-dimensional effects in inclined struts provides more accurate results.

Bottle-shaped struts are not as critical in threedimensional plain concrete structures as they would be e.g. for deep beams, due to the effects of confinements from the surrounding concrete and the fact that a rather low radial spreading of the compressive stresses leads to a larger increase of the affected area as these stresses spread in the three directions.

The predictions from Alternative 3 based on a simplified two-dimensional analogy, are good in average but exhibit more scatter than with the Enhanced Model. 
The geometry proposed for three dimensional nodal zones in this work improves the consistency and accuracy of the model. This geometry ensures geometrical compatibility between the members and the concurrency between the centroids of the nodal regions and the axes of the struts and ties. It is believed that with this solution, nodal zones, the critical parts of reinforced concrete structures, are defined in a reliable way in three dimensional structures.

The program developed for the analysis of the pile caps automatically finds the optimal geometrical configuration for the strut-and-tie models in order to determine the maximum capacity of the pile caps. This process involves a large number of iterations, although the calculation time remains short as the calculations required are simple and fast to run.

The characteristics integrated into the Enhanced Model can be extended to pile caps with more complex shapes, different number and position of piles as well as other loading conditions. The Enhanced Model used to determine the maximum capacity of pile caps is also suitable to design new pile caps and optimize their dimensions or the amount of reinforcing steel required.

\section{Conclusions}

An enhanced and generic three-dimensional strutand-tie model has been developed in this work for the design of reinforced concrete pile caps and validated with experimental results from tests on four-pile caps found in the literature. The model effectively predicts the ultimate capacity of these pile caps.

The consistent three-dimensional geometrical definition proposed for the members of the strutand-tie model ensures an accurate verification at the nodal zones. The strength criterion for bottleshaped struts integrated in the model allows to take into account favourable confinement effects. An automatic iterative procedure has also been successfully applied to adjust the position of the members and to refine the dimensions of the nodal zones under the column with respect to the strength of concrete subjected to a triaxial state of stress.
This work indicates that the enhanced model developed here can lead to safe and less conservative design for pile caps.

\section{References}

[1] Schlaich J, Schäfer K, Jennewein M. Toward a Consistent Design of Structural Concrete. PCl J 1987; 32: 74-150.

[2] Adebar P, Zhou L (Zongyu). Design of Deep Pile Caps by Strut-and-Tie Models. Struct $J$ 1996; 93: 437-448.

[3] Souza R, Kuchma D, Park J, et al. Adaptable Strut-and-Tie Model for Design and Verification of Four-Pile Caps. ACl Struct J 2009; 106: 142-150.

[4] CEN. EN 1992-1-1 - Eurocode 2: Design of concrete structures - Part 1-1: General rules and rules for buildings. 2004.

[5] Adebar P, Zhou Z. Bearing Strength of Compressive Struts Confined by Plain Concrete. ACl Struct J 1993; 90: 534-541.

[6] Blévot J, Frémy R. Semelles sur Pieux Méthodes de calcul, compte rendu d'essais, dispositions constructives. Ann I'Institut Tech du bâtiment des Trav publiques 1967; 230: 223-294.

[7] Clarke JL. Behaviour and Design of Pile Caps with Four Piles. London, 1973.

[8] Sabnis GM, Gogate AB. Investigation of Thick Slab (Pile Cap) Behavior. $\mathrm{ACl} J$ Proc; 81. Epub ahead of print 1984. DOI: 10.14359/10638.

[9] Suzuki K, Otsuki K, Tsubata T. Influence of Bar Arrangement on Ultimate Strength of Four-Pile Caps. Trans Japan Concr Inst 1998; 20: 195-202.

[10] Suzuki K, Otsuki K, Tsuchiya T. Influence of Edge Distance on Failure Mechanism of Pile Caps. Trans Japan Concr Inst 2000; 22: 361-368. 